\title{
Photoinduced oxidation of sea salt halides by aromatic ketones: a source of halogenated radicals
}

\author{
A. Jammoul, S. Dumas, B. D'Anna, and C. George \\ Université de Lyon, Lyon, 69626, France; université Lyon 1, Lyon, 69626, France; CNRS, INSU, UMR5256, IRCELYON, \\ Institut de recherches sur la catalyse et l'environnement de Lyon, Villeurbanne, 69626, France \\ Received: 12 February 2009 - Published in Atmos. Chem. Phys. Discuss.: 24 March 2009 \\ Revised: 9 June 2009 - Accepted: 12 June 2009 - Published: 2 July 2009
}

\begin{abstract}
The interactions between triplet state benzophenone and halide anion species $\left(\mathrm{Cl}^{-}, \mathrm{Br}^{-}\right.$and $\left.\mathrm{I}^{-}\right)$have been studied by laser flash photolysis (at $355 \mathrm{~nm}$ ) in aqueous solutions at room temperature. The decay of the triplet state of benzophenone was followed at $525 \mathrm{~nm}$. Triplet lifetime measurements gave rate constants, $k_{q}\left(\mathrm{M}^{-1} \mathrm{~s}^{-1}\right)$, close to diffusion controlled limit for iodide $\left(\sim 8 \times 10^{9} \mathrm{M}^{-1} \mathrm{~s}^{-1}\right)$, somewhat less for bromide $\left(\sim 3 \times 10^{8} \mathrm{M}^{-1} \mathrm{~s}^{-1}\right)$ and much lower for chloride $\left(<10^{6} \mathrm{M}^{-1} \mathrm{~s}^{-1}\right)$. The halide $\left(\mathrm{X}^{-}\right)$quenches the triplet state; the resulting product has a transient absorption at $355 \mathrm{~nm}$ and a lifetime much longer than that of the benzophenone triplet state, is formed. This transient absorption feature matches those of the corresponding radical anion $\left(\mathrm{X}_{2}^{-}\right)$. We therefore suggest that such reactive quenching is a photosensitized source of halogen in the atmosphere or the driving force for the chemical oxidation of the oceanic surface micro layer.
\end{abstract}

\section{Introduction}

Oceans cover about $70 \%$ of the Earth's surface and provide a surface where exchange of gases and energy take place through complex mechanisms. The ocean's surface microlayer is particularly enriched in organics as revealed by chemical analysis, including amino acids, proteins, fatty acids, lipids, phenols, PAHs, and humic-type components (Cincinelli et al., 2001a, b). Such a complex chemical mixture is naturally reactive with a variety of functional groups, such as carbonyl and carboxylic acids (Sempere and Kawamura, 2003). The sea surface microlayer often has greater

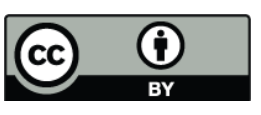

Correspondence to: C. George (christian.george@ircelyon.univlyon1.fr) concentrations of dissolved organic material (DOM) than subsurface water (Hunter and Liss, 1977). The chemical nature of this material includes hydrocarbon components, lipids, fulvic and humic acids which contains carbonyls group (Cincinelli et al., 2001a). The implications of the presence of such light-absorbing organics and the possible photochemical reactions are not yet well understood in the sea surface microlayer. But clearly, the presence of such photoactive compounds at the air/sea interfaces could give rise to photosensitized processes (Becker et al., 1995; Canonica et al., 2006, 2000, 2005; Das et al., 1981; Ivanov et al., 2005; Lathioor and Leigh, 2001; Lathioor et al., 1999; Leigh et al., 1996) which may also affect chemistry in the marine boundary layer (MBL) (Reeser et al., 2008). Previously, we showed that chlorophyll may be a photochemical source of halogenated radicals or the driving force for ozone deposition at low wind speed (Clifford et al., 2008).

Halide anions are highly abundant in the marine boundary layer (MBL) both in sea water and sea salt aerosols (Finlayson-Pitts, 2003). The predominant anion is chloride (with concentrations approaching $0.5-5.6 \mathrm{M}$ ); followed by bromide $(\sim 10 \mathrm{mM})$ and iodide at least $(\sim 1 \mu \mathrm{M})$ (von Glasow et al., 2003; Schweitzer et al., 2000). While halide anions are very stable, their corresponding oxidized forms (i.e., halogen atoms) are highly reactive and play an important role in the oxidation capacity of the MBL as discovered for the Arctic boundary layer (Barrie et al., 1988). Different halogen atom sources have been suggested, involving heterogeneous chemistry of $\mathrm{NO}_{y}$ or $\mathrm{O}_{3}$ on sea-salt aerosols, in sunlit snowpack, or the photolysis of halogenated organics. The photochemical reactions of ozone at the air-sea interface may also be a significant source of molecular chlorine (Oum et al., 1998). Regardless of their sources, once formed the halogen atoms then initiate a set of catalytic cycles destroying tropospheric

Published by Copernicus Publications on behalf of the European Geosciences Union. 
ozone (especially for $\mathrm{Br}$ and I cycles) or oxidizing hydrocarbons (as observed for $\mathrm{Cl}$ ). The importance of the halogen reactions in the lower troposphere during springtime is now well recognized (Ariya et al., 1999).

Despite their importance, halogen atom sources in the MBL are still an open question which requires further attention. A recent study by Reeser et al. (2008) identified that halide anions $\left(\mathrm{X}^{-}\right)$can be photochemically oxidized to the corresponding radical anions $\left(\mathrm{X}_{2}^{-}\right)$at the air/sea interface due to a chemical reaction involving chlorophyll. This oxidation process occurred under visible illumination (up to $700 \mathrm{~nm}$ ) and was facilitated by the presence of ozone. This study, considering chlorophyll as a proxy for the oceanic surface layer, clearly showed that photosensitized reactions may oxidize halides into atomic halogens.

The validity of such a complex proxy is questionable since chlorophyll is highly unstable in salt solutions. However photosensitized reactions may also be initiated by other species present in the surface microlayer (especially carbonyl containing compounds). In the present study benzophenone (BP) has been selected as a proxy for the aromatic carbonyl found in sea surface microlayer. Excited triplet states of aromatic ketones have been widely studied in photochemistry (Blanchi and Watkins, 1974; Encinas et al., 1985; Encinas and Scaiano, 1981; Grewer and Brauer, 1994; Haselbach et al., 1991; Jacques et al., 1997; Kajii et al., 1987). Photochemical transformations may occur as a result of absorption of light or via sensitized reactions. Numerous studies on aromatic ketones on photoinduced charge transfer or/and energy transfer (Benitez et al., 1997; Haag et al., 1984; Huang and Shu, 1995; Poznyak and Vivero, 2005; Wu and Masten, 2002). In this case, following light absorption, benzophenone is capable of generating reactive oxidant species, such as singlet oxygen $\mathrm{O}_{2}\left({ }^{1} \Delta_{g}\right)$ (Mehrdad et al., 2002a b), ketyl radical and others, which can oxidize a wide range of organic compounds (Blanchi and Watkins, 1974; Encinas et al., 1985; Encinas and Scaiano, 1981; Grewer and Brauer, 1994; Haselbach et al., 1991; Jacques et al., 1997; Kajii et al., 1987). This is especially relevant for the fate of organic matter in aquatic environments (Haag et al., 1984).

By applying laser flash photolysis, we aim to investigate the interactions between benzophenone (again a possible proxy for the aromatics in the oceanic surface layer) and halide anions by determining bimolecular rate constants for the quenching of excited benzophenone (BP*) by halide anions and their mixtures.

\section{Experimental}

\subsection{Laser flash photolysis}

Transient absorption kinetics following excitation of benzophenone containing solutions were studied using a laser flash photolysis apparatus of standard design (Reeser et al.,
2008). A frequency-tripled pulsed Nd:YAG laser ( $355 \mathrm{~nm}$ ) was used as the photolysis source. During these experiments, the laser was operated with an output of $35 \mathrm{~mJ}$ per pulse $\left(\sim 90 \mathrm{~mJ} / \mathrm{cm}^{2}\right)$. The laser output passed through the $4 \mathrm{~mm}$ length of a $0.45 \mathrm{~mL}$ quartz flow cell, which was mounted about $40 \mathrm{~cm}$ away from the laser head and was maintained at ambient temperature. The body of the cell was blackened so that only its windows were transparent to radiation. The near-Gaussian density profile of the laser beam led to a fairly uniform irradiation of solutions in the flow cell. All connections to the cell were either glass or PTFE tubing. The samples were pumped through the cell using a peristaltic pump, replenishing the cell content after the required laser pulses.

Transient species produced by the pulsed laser beam were monitored by means of time resolved absorption spectroscopy. A $150 \mathrm{~W}$ high pressure Xenon arc lamp was used for the light source. The attenuated lamp output passed through the long axis of the cell and illuminated the entrance slit of a $1 / 4 \mathrm{~m}$ monochromator equipped with a 2400 grooves $/ \mathrm{mm}$ grating, then was detected by a photomultiplier (Hamamatsu H7732-10). The PMT signal was passed through a high-speed current amplifier/discriminator, and the AC component recorded on a $100 \mathrm{MHz}$ storage oscilloscope. The digitized signal was then transferred to a microcomputer using an IEEE-488 connection. Typically 32 measurements of the intensity measured at $1 \mu \mathrm{s}$ following the laser pulse were averaged at each wavelength to generate a transient absorption spectrum. The full transient absorption spectrum was then reconstructed from the steady and transient signals. For construction of an absorption spectrum, measurements were repeated every $10 \mathrm{~nm}$; for the kinetics experiments three wavelengths $-525 \mathrm{~nm}, 370 \mathrm{~nm}$ and $340 \mathrm{~nm}$ - were employed for observing the decays of BP triplet state.

All experiments were carried out under pseudo first order conditions, with a large excess of the quencher with respect to the initial BP concentrations. The decay of the triplet excited state of BP can be described as follows (in the presence of a quencher):

$\frac{d\left[{ }^{3} \mathrm{BP}\right]}{d t}=-k_{1} \cdot\left[{ }^{3} \mathrm{BP}\right]$ with $k_{1}=k_{q} \cdot$ [Quencher $]$

The combination of the Beer-Lambert law with Eq. (1) leads to the following equation:

$$
A_{e}=\ln \left(\frac{I_{0}}{I}\right)=\varepsilon_{e} l\left[{ }^{3} \mathrm{BP}\right]_{0} e^{-k_{1} t} \text { or } \ln \left(A_{e}\right)=\mathrm{const}-k_{1} t
$$

where $A_{e}$ is the base-e absorbance, $\varepsilon_{e}$ the corresponding extinction coefficient, $l$ the optical pathway and $\left[{ }^{3} \mathrm{BP}\right]_{0}$ the initial concentration of the triplet state.

The pseudo first order rate constant, $k_{1}$, is obtained from the slope of a logarithmic plot of the transient signals, plotted logarithmically as suggested in Eq. (2). Figure 1a shows a typical decay curve of the BP triplet state in presence of $6 \mathrm{mM}$ of sodium bromide at $298 \mathrm{~K}$ and $\mathrm{pH}=8$. A good linear 

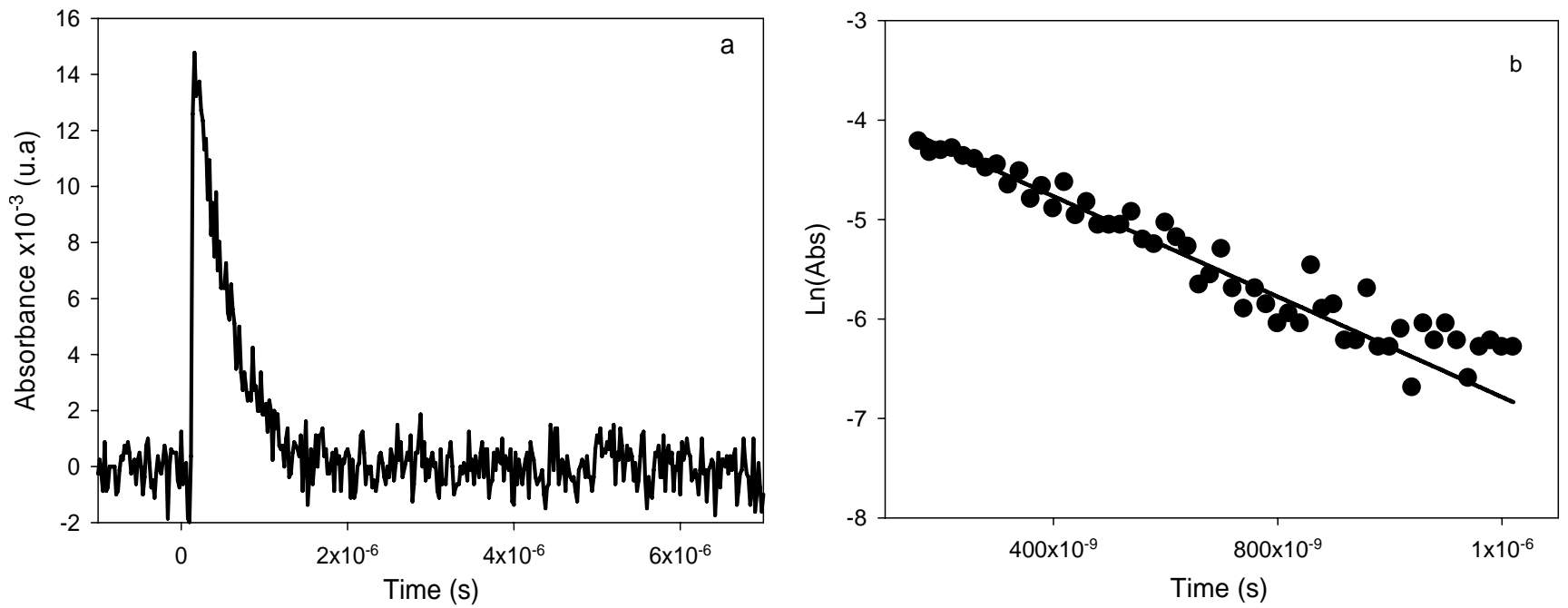

Fig. 1. (a) Transient absorption decay of the benzophenone triplet state $\left(\lambda_{\mathrm{obs}}=525 \mathrm{~nm}\right)$ in deoxygenated aqueous solutions containing $4 \mathrm{mM}$ of bromine. (b) Typical pseudo first order decay observed in the study of the ${ }^{3} \mathrm{BP}+\mathrm{Br}^{-}$reaction. The experimental conditions were as follow: $[\mathrm{BP}]=100 \mu \mathrm{M}, \mathrm{pH}=8$ at ambient temperature and 32 laser pulses averaged per data point.

fit to the data is obtained as demonstrated in Fig. 1b, indicating that the reaction takes effectively place under pseudo first order conditions.

All the experiments were performed at room temperature in the range $295-300 \mathrm{~K}$. Aqueous solutions containing $1 \mathrm{mM}$ of BP were deoxygenated with a stream of Argon for $20 \mathrm{~min}$. All solutions were freshly prepared using $18 \mathrm{M}$-ohm $\mathrm{cm}$ (Millipore) water. The chemicals used in this study were: benzophenone (Aldrich, 99\%), sodium chloride (Aldrich, $99+\%)$, sodium bromide $(99+\%)$, sodium iodide $(99+\%)$, sodium hydroxide solution (32\%; Riedel-de Haën); all were used without any further purification.

\subsection{Flow tube experiments}

A wetted-wall flow tube reactor followed by ion chromatography measurements was also used to determine whether halogen species were released into the gas phase as products of the suggested photosensitized reactions of BP with salt solutions. The experimental setup of the wetted wall flow tube is described in detail elsewhere (Clifford et al., 2008). A vertically-mounted Pyrex tube, $70 \mathrm{~cm}$ long and $1 \mathrm{~cm}$ internal diameter, was maintained at constant temperature using circulating thermostated water at $296 \mathrm{~K}$ through its outer jacket. Reagent solutions containing $100 \mu \mathrm{M}$ of BP, $0.01 \mathrm{M}$ of sodium bromide and $0.5 \mathrm{M}$ of sodium chloride at $\mathrm{pH}=1$ (acidified with hydrochloric acid) were injected at the top of the flow tube and evenly distributed by an annular reservoir dispenser system, leading to a homogeneous downward flow. The acidic conditions was chosen to increase the $\mathrm{Br}_{2}$ amount production (Frinak and Abatt, 2006). A synthetic air flow of $200 \mathrm{~mL} / \mathrm{min}$ was passed along its length. The flow tube was then irradiated using 4 fluorescent UV tubes (Black-
Light-Blue OSRAM Sylvania TLD15W/08), with output in the range $340-420 \mathrm{~nm}$ and $\lambda_{\max }=365 \mathrm{~nm}$ (Jammoul et al., 2007). The gas extracted from the flow tube passed through a bubbler containing $150 \mathrm{ml}$ of water at $\mathrm{pH}=13$, basified with sodium hydroxide. Any halogen molecules released into the gas phase during a reaction within the flowtube should then react with the hydroxyl anions in basic solution to give $\mathrm{X}^{-}$ and $\mathrm{XO}^{-}$. This is an indirect but efficient way of assessing qualitatively the presence of gaseous halogens such as $\mathrm{X}_{2}$ molecules ( $\mathrm{X}$ being any of the investigated halides), finally identified by ion chromatography. Blank experiments (in darkness) were made to assess the quantity of $\mathrm{HCl}$ degassing out of the film under these acidic condition. The corresponding $\mathrm{Cl}^{-}$concentration is indicated in Fig. 6 at residence time $0 \mathrm{~s}$.

A Dionex DX-120 ion chromatograph instrument equipped with a Dionex AS40 autosampler and a conductimeter detector was used for these measurements. The determination of anions $\left(\mathrm{X}^{-}\right)$was performed using a (PAC ion AS14A) column $(4 \mathrm{~mm} \times 250 \mathrm{~mm})$ and a mixture of $\mathrm{Na}_{2} \mathrm{CO}_{3} / \mathrm{NaHCO}_{3}(8 \mathrm{mM} / 1 \mathrm{mM})$ as eluent at a flow rate of $1 \mathrm{~mL} / \mathrm{min}$.

\section{Results and discussion}

\subsection{Quenching rate}

Excited triplet states of aromatic ketones are known to be strong oxidants; this has been studied with different electron donating compounds such as phenol (Canonica et al., 2006, 2000; Leigh et al., 1996) and oxygen (Mehrdad et al., 2002a, b). Immediately after the laser pulse a new spectrum, 


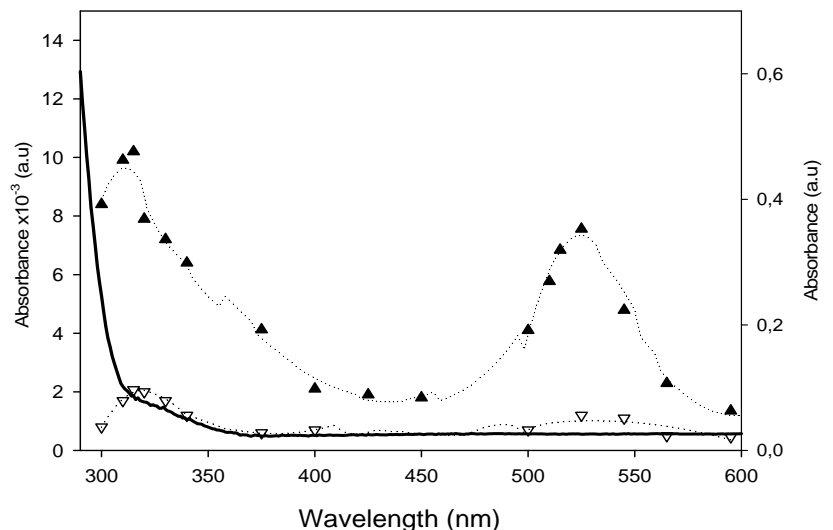

Fig. 2. Transient absorption spectra of aqueous deoxygenated solutions of $\mathrm{BP}(0.1 \mathrm{mM})$ at room temperature recorded after the $355 \mathrm{~nm}$ laser pulses. The filled and empty triangles represent respectively the BP triplet state at $1 \mu \mathrm{s}$ and $8 \mu \mathrm{s}$ after the pulse. The absorption spectrum of the employed benzophenone Aldrich in solution $\left(10^{-4} \mathrm{M}\right)$ is shown as a solid line (right scale).

displayed as solid symbols in Fig. 2, showing two absorption maxima around 310 and $525 \mathrm{~nm}$, was observed. These transient absorption features correspond to the absorption spectra of the benzophenone triplet state previously reported (Bensasson and Gramain, 1980).

Monitoring the decay rate of both absorption bands enables the determination of the lifetime of the triplet state. First of all, these decay rates were observed to be monoexponentials, leading to a triplet lifetime $\tau_{0}=6.0 \pm 0.5 \mu \mathrm{s}$ (simply defined as the inverse of the first order rate constant) in the absence of quenchers. Figure 2 shows that most of the absorption of benzophenone triplet state decreases substantially $8 \mu$ s after the laser pulse (open symbols). In the presence of halide anions, the decay of the BP transient absorption measured at $525 \mathrm{~nm}$ remains monoexponential, but becomes significantly more rapid with increasing anion concentration. The measured dependence of the decay rate on the halide anion concentration is displayed in Fig. 3 for the quenching of triplet $\mathrm{BP}$ by $\mathrm{Cl}^{-}, \mathrm{Br}^{-}, \mathrm{I}^{-}$and a mixture of $\mathrm{Br}^{-} / \mathrm{Cl}^{-}$at ambient temperature and $\mathrm{pH}=8$. From the slopes of the pseudofirst order decay rate $\mathrm{k}^{1}\left(\mathrm{~s}^{-1}\right)$ of ${ }^{3} \mathrm{BP}$ versus the halide concentration (Fig. 3), the quenching rate constant, $k_{q}$, may be determined using equation III:

$k_{1}=k_{q}\left[\mathrm{X}^{-}\right]+$const

The corresponding quenching rate constants obtained for the different quenchers are summarized in Table 1 . The $k_{q}$ values are in reasonably good agreement with the values obtained by Hurley et al. (1988) and Shizuka et al. (1982) in aqueous and acetonitrile media. The difference $(20-50 \%)$ is probably due to an ionic strength effect (Douglas et al., 1990; Morrison et al., 1996) or to a solvent effect (Burget and Jacques, 1998; Gutierrez, 2008). The large magnitude of the $k_{q}$ values determined for iodide and bromide strongly suggests that

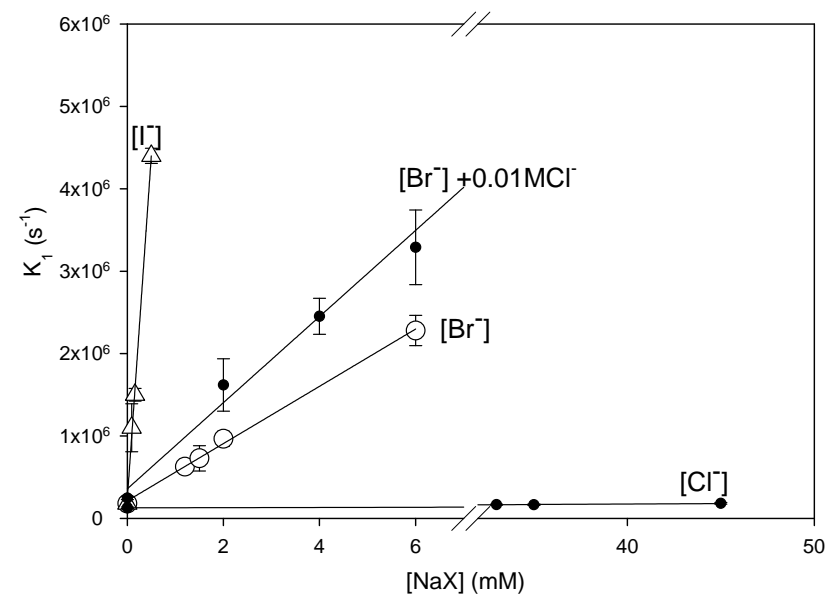

Fig. 3. Stern-Volmer plot of the pseudo-first order rate constants as a function of the anion concentrations for the quenching of BP triplet state in deoxygenated aqueous solutions monitored at $525 \mathrm{~nm}$ at room temperature. Benzophenone concentration $(0.1 \mathrm{mM})$ laser energy $25 \mathrm{~mJ}$. Error bars are calculated as three times the standard deviation of the least squares slope from analysis.

benzophenone quenching by these anions is highly efficient and potentially close to the rate diffusion constant (especially for iodide); on the other hand quenching by chloride is much less efficient.

In order to approach more realistic oceanic conditions, a mixture of a small amount of bromide and an excess of chloride was studied. Solutions are prepared with $100 \mu \mathrm{M}$ BP containing a fixed concentration of sodium chloride $(0.01 \mathrm{M})$ and varying concentration of sodium bromide (from 0 to $6 \mathrm{mM}$ ). Under these conditions, the measured triplet state quenching rate constant obtained is 1.5 times faster than with bromide alone. This slight change could be due to the ionic medium variation or to coupled $\mathrm{Cl} / \mathrm{Br}$ chemistries.

To test whether benzophenone triplet state deactivation by the anions can be explained by an electron transfer mechanism, we investigated the possibility of a correlation between the measured quenching rates constants and the associated free energies. Electron transfer between a halogen anion and the triplet state of benzophenone can be decomposed into different steps (see reaction below). First, the species diffuse together, allowing the formation of a contact complex ${ }_{1,3}\left(\mathrm{Ph}_{2} \mathrm{CO} * \ldots \mathrm{X}^{-}\right)$. Then, an intramolecular electron transfer takes place leading to an ion pair ${ }^{1,3}\left(\mathrm{Ph}_{2} \mathrm{C}^{\bullet}-\mathrm{O}^{-} \ldots \mathrm{X}^{\bullet}\right)$. At this point, two fates are possible: charge separation, leading to the separated radical, or a return to the initial state (back electron transfer). 
Table 1. Rate constants for quenching of benzophenone triplet by different sea salt halogens and mixture of anions, oxidation potentials for the anions, the free energy of the electron transfer $\Delta \mathrm{G}$, and a comparison of the quenching rate constant with the previous studies. The errors given as $95 \%$ confidence intervals estimated from the data fits.

\begin{tabular}{|c|c|c|c|c|}
\hline Quencher & Conditions & $K_{q}\left(\mathrm{M}^{-1} \mathrm{~s}^{-1}\right)$ & $\begin{array}{l}E\left(\mathrm{X}^{-} / \mathrm{X}\right)(\mathrm{V}) \\
\text { (Murov et al., 1993) }\end{array}$ & $\Delta G_{E T}(\mathrm{eV})$ \\
\hline I- & $\begin{array}{l}\mathrm{pH}=5.5 \text { water } \\
\mathrm{pH}=11 \text { water } \\
\text { acetonitrile/water }\end{array}$ & $\begin{array}{l}(8.2 \pm 0.8) \times 10^{9} \text { this work } \\
2.3 \times 10^{9}(\text { Hurley et al., } 1988) \\
3.5 \times 10^{9} \text { (Shizuka and Obuchi, 1982) }\end{array}$ & 0.535 & -1.165 \\
\hline $\mathrm{Br}-$ & $\begin{array}{l}\mathrm{pH}=8 \text { water } \\
\mathrm{pH}=11 \text { water } \\
\text { acetonitrile/water }\end{array}$ & $\begin{array}{l}(3.5 \pm 0.3) \times 10^{8} \text { this work } \\
2.2 \times 10^{8}(\text { Hurley et al., } 1988) \\
5.0 \times 10^{7} \text { (Shizuka and Obuchi, 1982) }\end{array}$ & 1.087 & -0.613 \\
\hline $\mathrm{Cl}-$ & $\begin{array}{l}\mathrm{pH}=5.5 \text { water } \\
\mathrm{pH}=11 \text { water } \\
\text { acetonitrile/water }\end{array}$ & $\begin{array}{l}(7.3 \pm 2.1) \times 10^{5} \text { this work } \\
\sim 8.0 \times 10^{4} \text { (Hurley et al., 1988) } \\
2.2 \times 10^{5} \text { (Shizuka and Obuchi, 1982) }\end{array}$ & 1.36 & -0.34 \\
\hline $\mathrm{Br}-/ \mathrm{Cl}-$ & $\begin{array}{l}\mathrm{pH}=5.5 \text { water } \\
{\left[\mathrm{Cl}^{-}\right]=0.01 \mathrm{M}}\end{array}$ & $(5.1 \pm 0.9) \times 10^{8}$ this work & & \\
\hline
\end{tabular}

a Referred to Pauling scale.

$$
\begin{aligned}
& \left(\mathrm{Ph}_{2} \mathrm{C}=\mathrm{O}\right)^{*}+\mathrm{X}^{-} \rightleftharpoons\left[\mathrm{X}^{-} \ldots{ }^{3}\left(\mathrm{Ph}_{2} \mathrm{C}=\mathrm{O}\right)\right] \\
& \rightleftharpoons\left[\mathrm{X}^{\bullet} \ldots\left(\mathrm{Ph}_{2} \mathrm{C}^{\bullet}-\mathrm{O}^{-}\right)\right]^{*} \\
& \leftrightharpoons \mathrm{Ph}_{2} \mathrm{C}^{\bullet}-\mathrm{O}^{-}+\mathrm{X}^{\bullet} \mathrm{orPh}_{2} \mathrm{CO}+\mathrm{X}^{-}
\end{aligned}
$$

The deactivation can take place by this mechanism only if the free energy of the electron transfer is negative (or very close to zero). This quantity may be calculated using the Rehm-Weller equation (Eq. 4) (Burget and Jacques, 1998; Gutierrez, 2008):

$$
\Delta G_{E_{T}}=F\left(E\left(\mathrm{X}^{-} / \mathrm{X}\right)-E_{1 / 2}(\mathrm{BP})-E_{T}(\mathrm{BP})\right)+\mathrm{C}
$$

where $E\left(\mathrm{X}^{-} / \mathrm{X}\right), E_{1 / 2}$ and $E_{T}$ correspond respectively to the oxidation potential of the anion $\mathrm{X}^{-}$, the reduction potential, and the triplet state energy of the benzophenone photosensitizer: $E_{1 / 2}(\mathrm{BP})=-1.3 \mathrm{~V}$ and $E_{T}(\mathrm{BP})=3 \mathrm{~V}$ (Murov et al., 1993). The entropic variation and the coulombic term (C) are considered here as negligible.

The calculated values of $\Delta G_{E T}$ are shown in Table 1 . The formation of charge transfer complex is thermodynamically favorable $\left(\Delta G_{E T}<0\right)$ for iodide and bromide and unfavorable $\left(\Delta G_{E T} \sim 0\right)$ for chloride. These results are consistent with the measured values of $k_{q}$ as a rapid electron transfer (quenching) has been measured for the better electron donor iodine, a somewhat lower rate for bromide, and a much slower rate for chloride, which displays unfavorable thermochemistry.

\subsection{Transient absorption of products in solution}

The electron transfer mechanism proposed above implies the formation of iodine and bromine atom radicals as products.

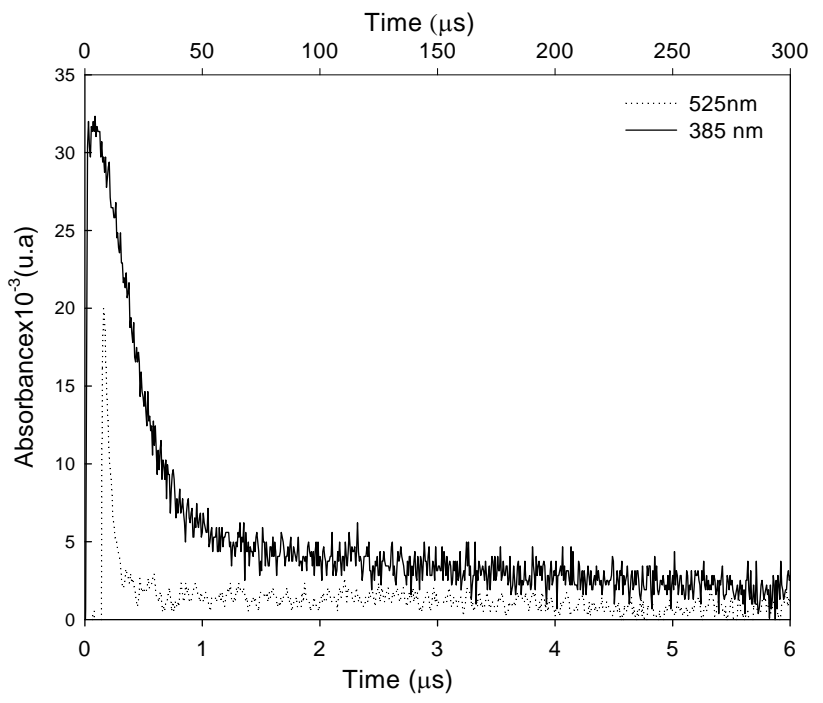

Fig. 4. Transient decay at $525 \mathrm{~nm}$ (dotted line, bottom scale) and $385 \mathrm{~nm}$ (solid line, top scale) obtained after irradiating with $355 \mathrm{~nm}$ laser pulse a deoxygenated solution containing $0.1 \mathrm{mM}$ of benzophenone and $0.5 \mathrm{mM}$ of potassium iodide in acetonitrile media.

To test this, we carried out transient absorption experiments in order to observe the radical $\mathrm{X}^{\bullet}$ and the benzophenone ketyl radical, $\mathrm{Ph}_{2} \mathrm{C}^{\bullet}-\mathrm{O}^{-}$. The identification of radical products was only carried out with iodide and bromide solutions, since the initial experiments showed that no radical products were observed following the excitation of benzophenone in solution containing chloride. It must be underlined that no transient species were observed in the absence of the photosensitizer. 


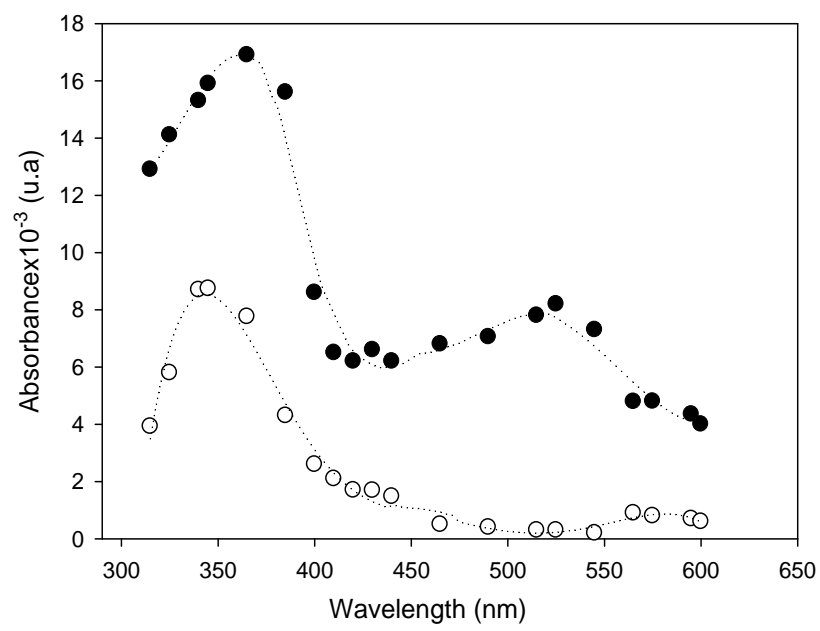

Fig. 5. Transient absorption spectra of aqueous deoxygenated solutions of $\mathrm{BP}(0.1 \mathrm{mM})$ and $\mathrm{NaBr}(2 \mathrm{mM})$ at room temperature recorded after laser excitation $(\lambda=355 \mathrm{~nm})$. The filled circles represent the initial spectrum $(1 \mu$ s after the pulse $)$ of $\left(\mathrm{BP}+\mathrm{Br}^{-}\right)$and the empty circles represent the absorption spectrum of the new transient $8 \mu$ s after the pulse.

\subsubsection{Iodide}

The ketyl and iodine radicals were not observed in aqueous media having BP concentrations of $0.1 \mathrm{mM}$. However, at a much lower benzophenone concentration $(1 \mu \mathrm{M})$, a transient absorption spectrum with a maximum at $380 \mathrm{~nm} \mathrm{~nm}$ was measured; this was previously been assigned to the iodine anion radical $\mathrm{I}_{2}^{\bullet-}$ (Devonshire and Weiss, 1968). The observation that $\mathrm{I}_{2}^{\bullet-}$ is only formed at very low BP concentrations may be due to a solvent effect on the quenching rate. A possible reaction can occur between the iodine radicals and benzophenone, therefore preventing the $\mathrm{I}_{2}^{\bullet-}$ formation. In addition, we looked for the formation of iodine radicals in acetonitrile solutions containing $0.1 \mathrm{mM}$ of BP. Immediately following the laser pulse, we observed clear indications of $I_{2}^{\bullet-}$ iformation under these conditions. A strong, very longlived feature appeared at $385 \mathrm{~nm}$ as shown as the solid line in Fig. 4. The transient signal observed at $525 \mathrm{~nm}$ (due to absorption by the triplet state of BP) is shown as well, for comparison. The feature observed at $385 \mathrm{~nm}$ is ascribed to $\mathrm{I}_{2}^{\bullet-}$ which exhibits absorption bands at 385 and $725 \mathrm{~nm}$ (Devonshire and Weiss, 1968). $I_{2}^{\bullet-}$ is expected to be the only absorbing species at $385 \mathrm{~nm}$; it has a reported lifetime of approximately $25 \mu$ s (Devonshire and Weiss, 1968). Thus, we conclude that either acetonitrile solvent may promote electron transfer between triplet benzophenone and iodine anion or that halogen radical formation is more stabilized (longer lived) in acetonitrile than in aqueous solution.

\subsubsection{Bromide}

The formation of a new transient species has been clearly observed subsequent to the quenching of benzophenone by the bromide anion. The spectra of the observed transients in solutions containing $\mathrm{BP}(0.1 \mathrm{mM})$ and $\mathrm{Br}^{-}(2 \mathrm{mM})$ are shown in Fig. 5 at 1 and $8 \mu$ s after the laser pulse at $355 \mathrm{~nm}$. The absorption maxima lie around 350 and $525 \mathrm{~nm}$. The transient absorption spectrum is characterised by a broad band feature, from 450 to $600 \mathrm{~nm}$ corresponding to ${ }^{3} \mathrm{BP}$ and benzophenone ketyl radical (Bensasson and Gramain, 1980; Sakamoto et al., 2004) and a intense band at short wavelength $(<400 \mathrm{~nm})$. After $8 \mu \mathrm{s}$ when the triplet benzophenone is relaxed, the absorption at $350 \mathrm{~nm}$ is still apparent and long-lived (with a lifetime of ca. $15 \pm 0.5 \mu \mathrm{s}$ ) and may correspond to bromine radical anion $\mathrm{Br}_{2}^{\circ-}$ (Ershov and Janata, 2003; Ershov et al., 2002; Grodkowski and Neta, 2002; Hurley et al., 1988; Zehavi and Rabani, 1972). This radical anion is known to absorb light from 300 to $400 \mathrm{~nm}$ with maximum absorption at $355 \mathrm{~nm}$.

\subsection{Reaction mechanisms}

The results presented above are consistent with a mechanism in which oxidation is initiated by an electron transfer from the anion $\mathrm{X}^{-}$to the excited triplet state of BP, yielding a halogen radical $\mathrm{X}^{\bullet}$ and a deprotonated ketyl radical $\left(\mathrm{Ph}_{2} \mathrm{C}^{\bullet}=\mathrm{O}^{-}\right)$. We propose that all the observations presented above can be explained with the following mechanism:

$$
\begin{aligned}
& \left(\mathrm{Ph}_{2} \mathrm{CO}\right)^{*}+\mathrm{X}^{-} \rightarrow \mathrm{Ph}_{2} \mathrm{C}^{\bullet} \mathrm{O}^{-}+\mathrm{X}^{\bullet} \\
& \mathrm{X}^{\bullet}+\mathrm{X}^{-} \rightleftharpoons \mathrm{X}_{2}^{\bullet-} \\
& \mathrm{X}_{2}^{\bullet-}+\mathrm{Ph}_{2} \mathrm{CO} \rightarrow \text { products } \\
& \mathrm{X}^{\bullet}+\mathrm{Ph}_{2} \mathrm{CO} \rightarrow \text { products } \\
& \mathrm{X}_{2}^{\bullet-}+\mathrm{X}_{2}^{\bullet-} \rightarrow \mathrm{X}_{2}+2 \mathrm{X}^{-} \\
& \mathrm{X}_{2} \rightleftharpoons \mathrm{X}_{2}(\mathrm{~g})
\end{aligned}
$$

In the presence of a large excess of $\mathrm{X}^{-}$, the halogen radical $\mathrm{X}^{\bullet}$ may react with $\mathrm{X}^{-}$ions and form $\mathrm{X}_{2}^{\bullet-}$ radical anions $\mathrm{Re}$ action (R2). The $\mathrm{X}^{\bullet}$ and $\mathrm{X}_{2}^{\bullet-}$ radicals are strong oxidants and will react with the surrounding organic compounds by electron transfer and $\mathrm{H}$-abstraction Reactions (R3 and R4) with rates which depend on the difference in the redox potentials of the reagents (Gilbert et al., 1988;H asegawa and Neta, 1978; Martire et al., 2001).

In solutions which contain both sodium chloride and small amounts of sodium bromide, one would expect that the very much faster reaction with bromide (see Table 1) might dominate over reaction with chloride, except when the $\mathrm{Cl}^{-} / \mathrm{Br}^{-}$ ratio is below $\sim 10$. Indeed, in mixed chloride-bromide solutions, it appears that the quenching of ${ }^{3} \mathrm{BP}$ is dominated 
by the bromide anion, as inferred from the rapid deactivation rate. In this case, the mechanism of $\mathrm{Br}_{2}$ and $\mathrm{BrCl}$ formation may occur via (Ershov et al., 2002).

$\mathrm{Br}^{\bullet}+\mathrm{Cl}^{-} \rightarrow \mathrm{BrCl}^{\bullet-}+\mathrm{Br}^{-} \rightarrow \mathrm{Br}_{2}^{\bullet-}+\mathrm{Cl}^{-}$

This reaction mechanism produces, by a photosensitized process, atomic halogen as recently highlighted in the case of illuminated chlorophyll reacting with sea-salt anions. The present paper confirms this previous study (Reeser et al., 2008) and underlines that such process may occur with different photosensitizers.

\subsection{Formation of gas phase products}

We investigated the possible production of gas phase $X_{2}$ or $\mathrm{XY}$ (X, Y are halogen atoms), implied by Reaction (R8) above, using the flowtube apparatus. At its exit, both $X_{2}$ and $\mathrm{XY}$ will react in the alkaline bubbler with the hydroxyl anion $\left(\mathrm{OH}^{-}\right)$, giving rise to bromide or chloride anions which are then detectable by ion chromatography.

The formation of $\mathrm{X}_{2}$ or in the flow-tube was monitored at $295 \pm 2 \mathrm{~K}$ as a function of the injector position (which is proportional to the residence time in the tube), using a solution containing a $\left[\mathrm{Cl}^{-}\right]:\left[\mathrm{Br}^{-}\right]$molar ratio of $50: 1$. The result is shown in Fig. 6. We observe the presence of $\mathrm{X}^{-}$anions, which strongly implies the formation of $\mathrm{X}_{2}$. The concentration initially increases with the exposure time of the $\mathrm{BP} / \mathrm{salt}$ solution to illumination, but then is seen to decrease at long exposure time, though we did not make any measurements using an irradiation time of the liquid film of more than $42 \mathrm{~s}$. It is possible that, at the longer exposure times halogen molecules were still released into the gas phase, but at a concentration below the instrumental limit of detection of $15 \mathrm{ppbv}$, corresponding to $0.1 \mathrm{mg} / \mathrm{L}$ in solution. This decay could be simply observed by the heterogeneous chemistry of the gaseous dihalogens at the air/liquid interface in this wetted-wall flow tube. Alternatively it could be that the longer exposure times give rise to photochemical or evaporative loss of the benzophenone, thereby reducing its ability to act as a photosensitizer. To explore this issue, we measured the UV-visible absorption spectrum for solutions containing a benzophenone - halide anion mixture at different times of irradiation. We found that the amount of benzophenone decreased by $60 \%$ after $42 \mathrm{~s}$ of irradiation. This is mainly due to the volatility of benzophenone and its low solubility in water. On the other hand, this may also be due to reaction of BP with the reactive halogenated species formed following the electrons transfer.

\section{Conclusions}

In the present paper we have demonstrated that photosensitized reactions can occur due to the presence of photochemical agents in the sea surface microlayer. According to the

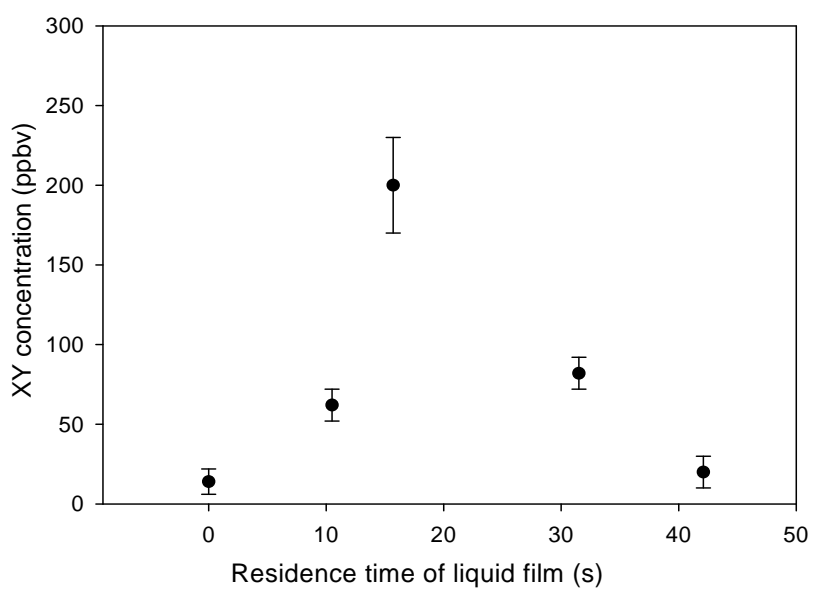

Fig. 6. Kinetics of the gaseous dihalogen production as a function of residence time of liquid film in the irradiated flowtube. The experiments are performed under UV irradiation (spectral irradiance $1.2 \times 10^{15}$ photons $\mathrm{cm}^{-2} \mathrm{~s}^{-1}$ in the $340-420 \mathrm{~nm}$ range) and the conditions were as follow: ambient temperature, $[\mathrm{BP}]=100 \mu \mathrm{Msg}[\mathrm{NaBr}]=0.01 \mathrm{M},[\mathrm{NaCl}]=0.5 \mathrm{M}$.

proposed mechanism, chemistry may be initiated by interactions between triplet state benzophenone and halide anions. We have measured the quenching rate constant of triplet BP by different sea salts; while chloride is not strongly reactive with the triplet state of BP, deactivation is very fast with iodide and somewhat less for bromide. The magnitude of the quenching rate constant follows a trend given by the values of the free energy for electron transfer. Thus electron transfer was shown to be the probable mechanism for the oxidation of sea salt anions by triplet BP. This mechanism leads to the formation of halogen molecules in the gas phase. We expect that such a photosensitized process initiated by carbonyl compounds may be relevant in the chemistry of the sea surface microlayer, not only for sea salt but also for any organic compound having a one electron oxidation potential. This has important implications for the chemistry in the MBL, because the activation of halides in seawater containing chlorophyll or organic carbonyl provides a catalytic loss mechanism for ozone. The latest measurements (Environmenta, 2009) show that the halogen may cause to decreasing ozone levels in the lower atmosphere over tropical oceans and probably above most other oceans. Indeed, the source of tropospheric gas-phase halogen is known to be heterogeneous in nature (E. M. Knipping et al., 2000). The omission of halogen sources and their chemistry in atmospheric models may lead to significant errors in calculations of global ozone budgets. The mechanism presented above could represent such a source for model calculations. We are currently undertaking experiments to quantify its potential importance.

Finally, the reaction of $\mathrm{Cl}$ (and, potentially, other halogens present as halides in seawater) or $\mathrm{OH}$ with organic compounds at the ocean's surface may be a source of halogenated 
or partially oxidized organic compounds, which might participate in new particle formation and growth in the MBL.

Acknowledgements. The support by the CNRS and INSU is acknowledged.

Edited by: J. Thornton

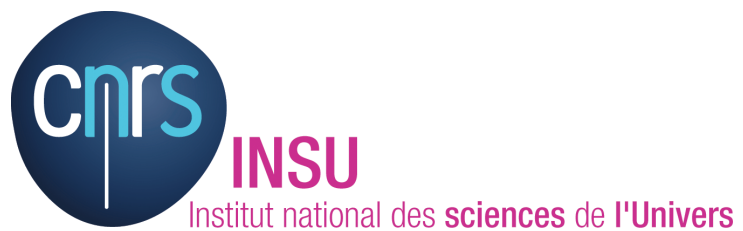

The publication of this article is financed by CNRS-INSU.

\section{References}

Ariya, P. A., Niki, H., Harris, G. W., Anlauf, K. G., and Worthy, D. E. J.: Polar sunrise experiment 1995: hydrocarbon measurements and tropospheric $\mathrm{Cl}$ and $\mathrm{Br}$-atoms chemistry, Atmos. Environ., 33, 931-938, 1999.

Barrie, L. A., Bottenheim, J. W., Schnell, R. C., Crutzen, P. J., and Rasmussen, R. A.: Ozone destruction and photochemical reactions at polar sunrise in the lower Arctic atmosphere, Nature, 334, 138-141, 1988.

Becker, H.-D., Burgdorff, C., and Loehmannsroeben, H.-G.: Intramolecular deactivation of photoexcited anthracenes by aromatic ketones, J. Photochem. Photobiol. A, 86, 133-139, 1995.

Benitez, F. J., Beltran-Heredia, J., Acero, J. L., and Pinilla, M. L.: Simultaneous photodegradation and ozonation plus UV radiation of phenolic acids - major pollutants in agro-industrial wastewaters, J. Chem. Technol. Biotechnol., 70, 253-260, 1997.

Bensasson, R. V. and Gramain, J. C.: Benzophenone triplet properties in acetonitrile and water, Reduction by lactams, Journal of the Chemical Society, Faraday Transactions 1: Physical Chemistry in Condensed Phases, 76, 1800-1810, 1980.

Blanchi, J. P. and Watkins, A. R.: Quenching of triplet benzophenone by electron donors, J. Chem. Soc., Chem. Commun., 265266, 1974.

Burget, D. and Jacques, P.: Unusual solvent effects on the fluorescence quenching rate constants of a thioxanthone derivative by n-butylamine and isoprene, Chem. Phys. Lett., 291, 207-214, 1998.

Canonica, S., Hellrung, B., and Wirz, J.: Oxidation of Phenols by Triplet Aromatic Ketones in Aqueous Solution, J. Phys. Chem. A., 104, 1226-1232, 2000.

Canonica, S., Kohn, T., Mac, M., Real, F. J., Wirz, J., and Von Gunten, U.: Photosensitizer Method to Determine Rate Constants for the Reaction of Carbonate Radical with Organic Compounds, Environ. Sci. Technol., 39, 9182-9188, 2005.

Canonica, S., Hellrung, B., Muller, P., and Wirz, J.: Aqueous oxidation of phenylurea herbicides by triplet aromatic ketones, Environ. Sci. Technol., 40, 6636-6641, 2006.

Cincinelli, A., Desideri, P. G., Lepri, L., Checchini, L., Del Bubba, M., and Udisti, R.: Marine contribution to the chemical composition of coastal and inland Antarctic snow, Int. J. Environ. Anal. Chem., 79, 283-299, 2001a.
Cincinelli, A., Stortini, A. M., Perugini, M., Checchini, L., and Lepri, L.: Organic pollutants in sea-surface microlayer and aerosol in the coastal environment of Leghorn-(Tyrrhenian Sea), Mar. Chem., 76, 77-98, 2001b.

Clifford, D., Donaldson, D. J., Brigante, M., D'Anna, B., and George, C.: Reactive uptake of ozone by chlorophyll at aqueous surfaces, Environ. Sci. Technol., 42, 1138-1143, 2008.

Das, P. K., Encinas, M. V., and Scaiano, J. C.: Laser flash photolysis study of the reactions of carbonyl triplets with phenols and photochemistry of p-hydroxypropiophenone, J. Am. Chem. Soc. 103, 4154-4162, 1981.

Devonshire, R. and Weiss, J. J.: Nature of the transient species in the photochemistry of negative ions in aqueous solution, J. Phys. Chem., 72, 3815-3820, 1968.

Douglas, P., Waechter, G., and Mills, A.: Ionic strength effects on the ground state complexation and triplet state electron transfer reaction between Rose Bengal and methyl viologen, Photochem. Photobiol., 52, 473-479, 1990.

Knipping, E. M., Lakin, M. J., Foster, K. L., Jungwirth, P., Tobias, D. J., Gerber, R. B., Dabdub, D., and Finlayson-Pitts, B. J.: Experiments and Simulations of Ion-Enhanced Interfacial Chemistry on Aqueous NaCl Aerosols, Science, 288, 301-306, 2000.

Encinas, M. V. and Scaiano, J. C.: Reaction of benzophenone triplets with allylic hydrogens. Laser flash photolysis study, J. Am. Chem. Soc., 103, 6393-6397, 1981.

Encinas, M. V., Lissi, E. A., and Olea, A. F.: Quenching of triplet benzophenone by vitamins $\mathrm{E}$ and $\mathrm{C}$ and by sulfur-containing amino acids and peptides, Photochem. Photobiol., 42, 347-352, 1985.

Environmenta, U. N. E. P.: Environmental effects of ozone depletion and its interactions with climate change: Progress report, Photochem. Photobiol. Sci., 8, 13-22, 2009.

Ershov, B. G., Kelm, M., Gordeev, A. V., and Janata, E.: A pulse radiolysis study of the oxidation of $\mathrm{Br}$ - by $\mathrm{Cl} 2$.bul.- in aqueous solution: formation and properties of ClBr.bul, Phys. Chem. Chem. Phys., 4, 1872-1875, 2002.

Ershov, B. G. and Janata, E.: The reduction of I2 by 1-hydroxyalkyl radicals in aqueous solution. A pulse radiolysis study, Chem. Phys. Lett., 372, 195-198, 2003.

Finlayson-Pitts, B. J.: The tropospheric chemistry of sea salt: a molecular-level view of the chemistry of $\mathrm{NaCl}$ and $\mathrm{NaBr}$, Chemical reviews, 103, 4801-4822, 2003.

Frinak, E. K. and Abbatt, J. P. D.: $\mathrm{Br}^{2}$ production from the heterogeneous reaction of gas-phase $\mathrm{OH}$ with aqueous salt solutions: Impacts of acidity, halide concentration, and organic surfactants, J. Phys. Chem. A., 110(35), 10456-10464, 2006.

Gilbert, B. C., Stell, J. K., Peet, W. J., and Radford, K. J.: Generation and reactions of the chlorine atom in aqueous solution, Journal of the Chemical Society, Faraday Transactions 1: Physical Chemistry in Condensed Phases, 84, 3319-3330, 1988.

Grewer, C. and Brauer, H.-D.: Mechanism of the Triplet-State Quenching by Molecular Oxygen in Solution, J. Phys. Chem., 98, 4230-4235, 1994.

Grodkowski, J. and Neta, P.: Formation and Reaction of Br.bul.-2 Radicals in the Ionic Liquid Methyltributylammonium Bis(trifluoromethylsulfonyl)imide and in Other Solvents, J. Phys. Chem. A, 106, 11130-11134, 2002.

Gutierrez, M. I.: Solvent effect on the physical quenching of singlet molecular oxygen by p-quinones, Photochem. Photobiol. Sci., 7 , 
480-484, 2008.

Haag, W. R., Hoigne, J. R., Gassman, E., and Braun, A. M.: Singlet oxygen in surface waters - Part I: Furfuryl alcohol as a trapping agent, Chemosphere, 13, 631-640, 1984.

Hasegawa, K. and Neta, P.: Rate constants and mechanisms of reaction of chloride (Cl2-) radicals, J. Phys. Chem., 82, 854-857, 1978.

Haselbach, E., Jacques, P., Pilloud, D., Suppan, P., and Vauthey, E.: Quenching of triplet benzophenone by 1,4diazabicyclo[2.2.2] octane in acetonitrile revisited, J. Phys. Chem., 95, 7115-7117, 1991.

Huang, C.-R. and Shu, H.-Y.: The reaction kinetics, decomposition pathways and intermediate formations of phenol in ozonation, $\mathrm{UV} / \mathrm{O}_{3}$ and $\mathrm{UV} / \mathrm{H}_{2} \mathrm{O}_{2}$ processes, J. Hazard. Mater., 41, 47-64, 1995.

Hunter, K. A. and Liss, P. S.: Input of organic material to oceans - air-sea interactions and organic chemical composition of seasurface, Mar. Chem., 5, 361-379, 1977.

Hurley, J. K., Linschitz, H., and Treinin, A.: Interaction of halide and pseudohalide ions with triplet benzophenone-4-carboxylate: kinetics and radical yields, J. Phys. Chem., 92, 5151-5159, 1988.

Ivanov, V., Kutsenova, A., and Khavina, E.: Chemical dynamics of radical pairs formed by benzophenone photoreduction in solid polymers, Russian Chemical Bulletin, 54, 1445-1448, 2005.

Jacques, P., Allonas, X., Von Raumer, M., Suppan, P., and Haselbach, E.: Quenching of triplet benzophenone by methyl and methoxy benzenes: are triplet exciplexes involved?, J. Photochem. Photobiol. A., 111, 41-45, 1997.

Kajii, Y., Fujita, M., Hiratsuka, H., Obi, K., Mori, Y., and Tanaka, I.: Quenching of triplet benzophenone by 2,4,6-tri-tert-butylphenol and formation of its phenoxy radical, J. Phys. Chem., 91, 27912794, 1987.

Lathioor, E. C., Leigh, W. J., and St. Pierre, M. J.: Geometrical Effects on Intramolecular Quenching of Aromatic Ketone (p,p) Triplets by Remote Phenolic Hydrogen Abstraction, J. Am. Chem. Soc., 121, 11984-11992, 1999.

Lathioor, E. C., and Leigh, W. J.: Geometric and solvent effects on intramolecular phenolic hydrogen abstraction by carbonyl n,p* and p,p* triplets, Can. J. Chem., 79, 1851-1863, 2001.

Leigh, W. J., Lathioor, E. C., and St. Pierre, M. J.: Photoinduced Hydrogen Abstraction from Phenols by Aromatic Ketones. A New Mechanism for Hydrogen Abstraction by Carbonyl n,p and p,p Triplets, J. Am. Chem. Soc., 118, 12339-12348, 1996.

Martire, D. O., Rosso, J. A., Bertolotti, S., Le Roux, G. C., Braun, A. M., and Gonzalez, M. C.: Kinetic Study of the Reactions of Chlorine Atoms and Cl2.bul. - Radical Anions in Aqueous Solutions. II. Toluene, Benzoic Acid, and Chlorobenzene, J. Phys. Chem. A., 105, 5385-5392, 2001.
Mehrdad, Z., Noll, A., Grabner, E.-W., and Schmidt, R.: Sensitization of singlet oxygen via encounter complexes and via exciplexes of pp* triplet excited sensitizers and oxygen, Photochem. Photobiol. Sci., 1, 263-269, 2002a.

Mehrdad, Z., Schweitzer, C., and Schmidt, R.: Formation of $\mathrm{O}_{2}(1 \mathrm{Sg}+), \mathrm{O}_{2}(1 \mathrm{Dg})$, and $\mathrm{O}_{2}(3 \mathrm{Sg}-)$ during Oxygen Quenching of np Triplet Phenyl Ketones: The Role of Charge Transfer and Sensitizer-Oxygen Complex Structure, J. Phys. Chem. A., 106, 228-235, 2002b.

Morrison, M. E., Dorfman, R. C., and Webber, S. E.: Fluorescence Quenching Kinetics of Phenanthrene Covalently Bound to Sodium Poly(acrylate-co-acrylamide): Effects of Ionic Strength and Counterion, J. Phys. Chem., 100, 15187-15197, 1996.

Murov, S. L., Carmichael, I., and Hug, G. L.: Handbook of Photochemistry 2nd edition, Marcel Decker inc., 1993.

Oum, K. W., Lakin, M. J., DeHaan, D. O., Brauers, T., and Finlayson-Pitts, B. J.: Formation of molecular chlorine from the photolysis of ozone and aqueous sea-salt particles, Science, 279, 74-77, 1998.

Poznyak, T. and Vivero, J.: Degradation of aqueous phenol and chlorinated phenols by ozone, Ozone Science and Engineering, 27, 447-458, 2005.

Reeser, D. I., Jammoul, A., Clifford, D., Brigante, M., D’Anna, B., George, C., and Donaldson, D. J.: Photoenhanced reactive uptake of gas phase ozone by chlorophyll at the sea-water surface, J. Phys. Chem. C., 113, 2071-2077, 2009.

Sakamoto, M., Cai, X., Hara, M., Tojo, S., Fujitsuka, M., and Majima, T.: Transient Absorption Spectra and Lifetimes of Benzophenone Ketyl Radicals in the Excited State, J. Phys. Chem. A., 108, 8147-8150, 2004.

Schweitzer, F., Mirabel, P., and George, C.: Uptake of hydrogen halides by water droplets, J. Phys. Chem. A., 104, 72-76, 2000.

Sempere, R. and Kawamura, K.: Trans-hemispheric contribution of C2-C10 a, w-dicarboxylic acids, and related polar compounds to water-soluble organic carbon in the western Pacific aerosols in relation to photochemical oxidation reactions, Global Biogeochem. Cy., 17, 38/31-38/15, 2003.

Shizuka, H. and Obuchi, H.: Anion-induced triplet quenching of aromatic ketones by nanosecond laser photolysis, J. Phys. Chem., 86, 12971302, 1982.

von Glasow, R., Crutzen, P. J., Heinrich, D. H., and Karl, K. T.: Tropospheric Halogen Chemistry, in: Treatise on Geochemistry, Pergamon, Oxford, 1-67, 2003.

$\mathrm{Wu}$, J. J. and Masten, S. J.: Oxidation kinetics of phenolic and indolic compounds by ozone: applications to synthetic and real swine manure slurry, Water Res., 36, 1513-1526, 2002.

Zehavi, D. and Rabani, J.: Oxidation of aqueous bromide ions by hydroxyl radicals, Pulse radiolytic investigation, J. Phys. Chem., 76, 312-319, 1972. 